\title{
EXTENDED TARGET WEIGHING APPROACH (ETWA): IMPACT AND RISK ANALYSIS OF LIGHTWEIGHT CONCEPTS IN THE PRODUCT-PRODUCTION SYSTEM-CO- DESIGN
}

\author{
Albers, Albert (1); \\ Stürmlinger, Tobias (1); \\ Revfi, Sven (1); \\ Behdinan, Kamran (2) \\ 1: Karlsruhe Institute of Technology (KIT); \\ 2: University of Toronto - Department of Mechanical \& Industrial Engineering, Canada
}

\begin{abstract}
Lightweight design in interconnected systems becomes more and more complex as the interdependencies cannot be overseen by the product developer. Varying one component might not only influence the interfaces to other components but also the underlying production systems.

Therefore, this contribution focuses on the product/production interdependencies and how they can be supported within lightweight design. Based on a functional description of the product it is possible to derive new lightweight design solutions and also to evaluate the change propagation in the production system. For this, a method for the impact and risk analysis is integrated in the lightweight design method Extended Target Weighing Approach (ETWA). By doing so, a risk value for the adapted production system can be calculated and different design concepts can be compared.

The application of the developed method on a simplified use-case shows great potentials when evaluating the impact of a newly developed lightweight design solution on an already existing production system supporting the product development in decision making.
\end{abstract}

Keywords: Lightweight design, Product modelling / models, Integrated product development, ETWA, change impact

Contact:

Albers, Albert

Karlsruhe Institute of Technology (KIT)

IPEK Institute of Product Engineering

Germany

albert.albers@kit.edu

Cite this article: Albers, A., Stürmlinger, T., Revfi, S., Behdinan, K. (2021) 'Extended Target Weighing Approach (ETWA): Impact and Risk Analysis of Lightweight Concepts in the Product-Production System-Co-Design', in Proceedings of the International Conference on Engineering Design (ICED21), Gothenburg, Sweden, 16-20 August 2021. DOI:10.1017/pds.2021.415 


\section{INTRODUCTION}

The mass of a product is an important factor in all phases of the product life cycle (Ponn and Lindemann, 2011). Not only in the use phase, where lighter accelerated products have a lower energy consumption, but also in the production or transport phase. Therefore, lightweight design strategies and methods have been developed in the past to support product developers in the development of lightweight design solutions. Most of the methods have different objectives, but all of them can be said to contribute to at least one of the dimensions technology, economy or ecology (cf. Laufer et al. (2019)). All of the mentioned dimensions have in common that they are not only affected by the mass but also by the production of the product as product and production are closely related. To address all requirements in the product development of highly interconnected products, integrated product/production co-designs are needed.

Therefore, this paper investigates how production systems can be systematically integrated in lightweight design. A method is proposed that allows the consideration of production systems in the lightweight design concept generation in early phases of product development. With this, it is possible to assess potentials and risks of changing a product design for lightweight reasons with regard to the (existing) production system infrastructure. The aim of the method is the modelling of interdependencies of complex systems with little effort to evaluate development risks of alternative solutions at a very early stage in the product development process.

\section{STATE OF THE ART}

\subsection{Lightweight design \& Production}

In order to design lightweight products, product developers can rely on various lightweight design strategies (see e.g. Kopp et al. (2011)). These are used for the targeted application of design methods such as multi-material design (MMD). MMD, which means the right material in the right place to fulfill a desired function optimally, is a design method that is said to have great potential for exploiting the full lightweight design potential (Kopp et al., 2011). The use of different lightweight materials tailored to the load case results in a material mix in the system that poses challenges for product developers not only in design but also in the right choice of the corresponding production systems. Changes in product design usually lead to changes in the corresponding production system. According to Lindemann and Reichwald (1998), later changes in the design lead to higher costs. The "Rule of Ten" states, that costs of changes increase in each development stage by the factor 10 (Reinhart et al., 1996). One approach for the integrated development of the product and production system and therewith the reduction of development ime and costs is Simultaneous Engineering (Frankenberger $e t$ $a l ., 1998)$. The approach in this paper contributes to the early consideration of an integrated development of product and production system.

\subsection{The model of PGE - Product Generation Engineering}

Albers et al. (2015) state, that products are developed in generations. The description model of PGE Product Generation Engineering explains, that a product generation $G_{n}$ is developed with carryover variation $(\mathrm{CV})$, embodiment variation (EV) and principle variation (PV) from the reference system with its reference product $\mathrm{G}_{\mathrm{n}-1}$. Albers et al. (2020a) describe that other systems, e.g. production systems are varied in a similar way. It can be described with $\mathrm{CV}$ and $\mathrm{PV}$ as well and with attribute variations (AV). $\mathrm{AVs}$ can be a change of a tool in a machine or the change of production process parameters. It is the equivalent to EV in product development. A completely new development is a special case in the model of PGE, a Generation 1 development, in which no predecessor product element exists.

A higher share of new development of a product generation $G_{n}$ currently under development leads to an increased development risk. The new development share $\partial_{\mathrm{Nn}}$ consists of the combination of the share of the principle variation $\partial_{\mathrm{PV} n}$ and the share of the shape variation $\partial_{\mathrm{PV} n}$. (Albers et al., 2015).

\subsection{Extended Target Weighing Approach (ETWA)}

Large amounts of the later product weight are already determined by the choice of the product design in early phases of product development. In order to achieve the full lightweight design potential of products in early phases, the use of solution-open lightweight design methods based on functions is an appropriate approach. The first research work on function-based lightweight design methods was 
carried out by Feyerabend (1991), who transferred the classical approach of value analysis for cost optimization to lightweight design. Subsequently, further researchers dealt with function-based approaches in the context of lightweight design (Ponn and Lindemann, 2011; Posner et al., 2013). Albers et al. presented the Target Weighing Approach (TWA) in 2013, which supports the functionbased identification and evaluation of lightweight design potentials. The TWA takes into account the factors mass and cost. In recent years, however, the additional consideration of environmental influences has become more and more important, which is why Albers et al. (2017) developed the Extended Target Weighing Approach (ETWA). The ETWA additionally takes CO2 emissions into account and supports to achieve the mass, cost and $\mathrm{CO} 2$ targets of new product generations.
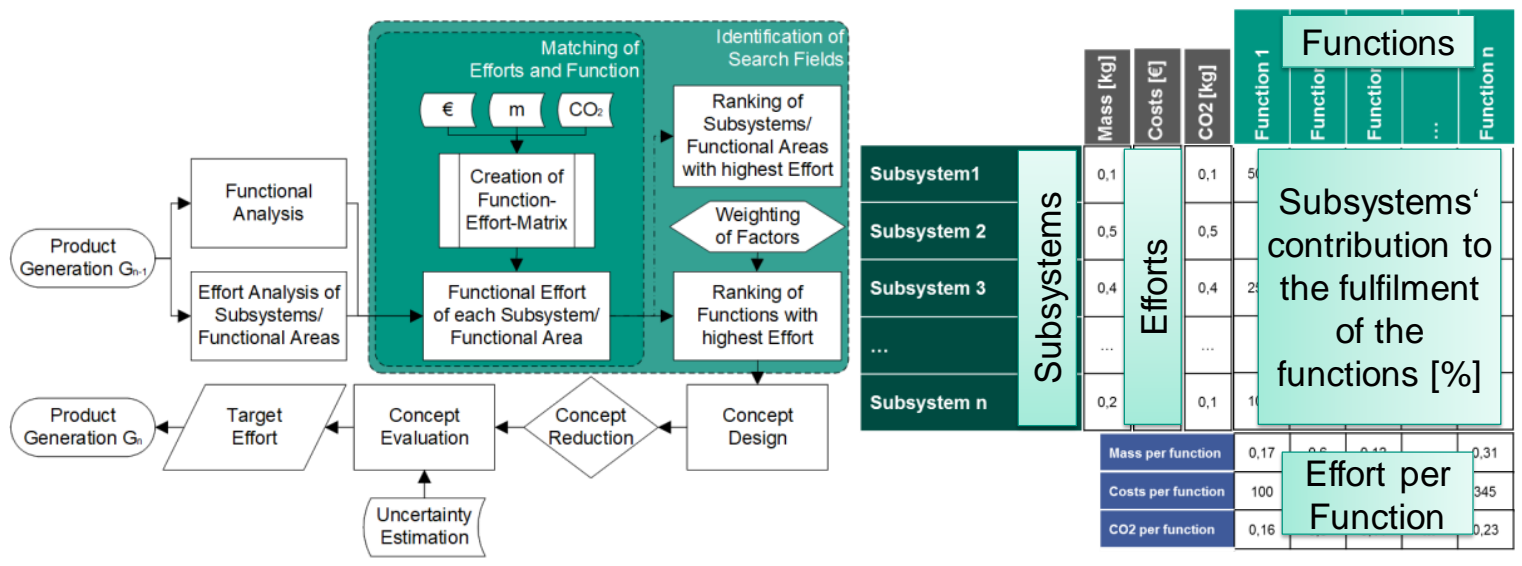

Figure 1. Workflow of the Extended Target Weighing Approach (left) according to Albers et al. (2020b) and Function-Effort-Matrix (right) according to Albers et al. (2018)

Figure 1 (left) shows the workflow of the ETWA. Based on a functional analysis of an existing product generation as an element of the reference system, the Function-Effort-Matrix (see Figure 1 (right)) assigns the percentage contributions of subsystems to the fulfillment of the functions. This allows the determination of functional masses, costs and $\mathrm{CO} 2$ emissions, which can be analyzed by additionally determining the relative importance of the previously identified functions, for example in a function portfolio (see Figure 2 (left)) or by benchmarking, which includes competitor products (see Figure 2 (right)). With the help of these analyzes, lightweight design potentials can be identified that are to be realized in new product generations through lightweight design approaches. The greatest potentials often result from the combination of different materials in a multi-material design. Therefore, an evaluation of the production systems required for the newly developed concepts is essential in order to be able to evaluate not only the impact on the product mass, but also on the production systems available to the company.
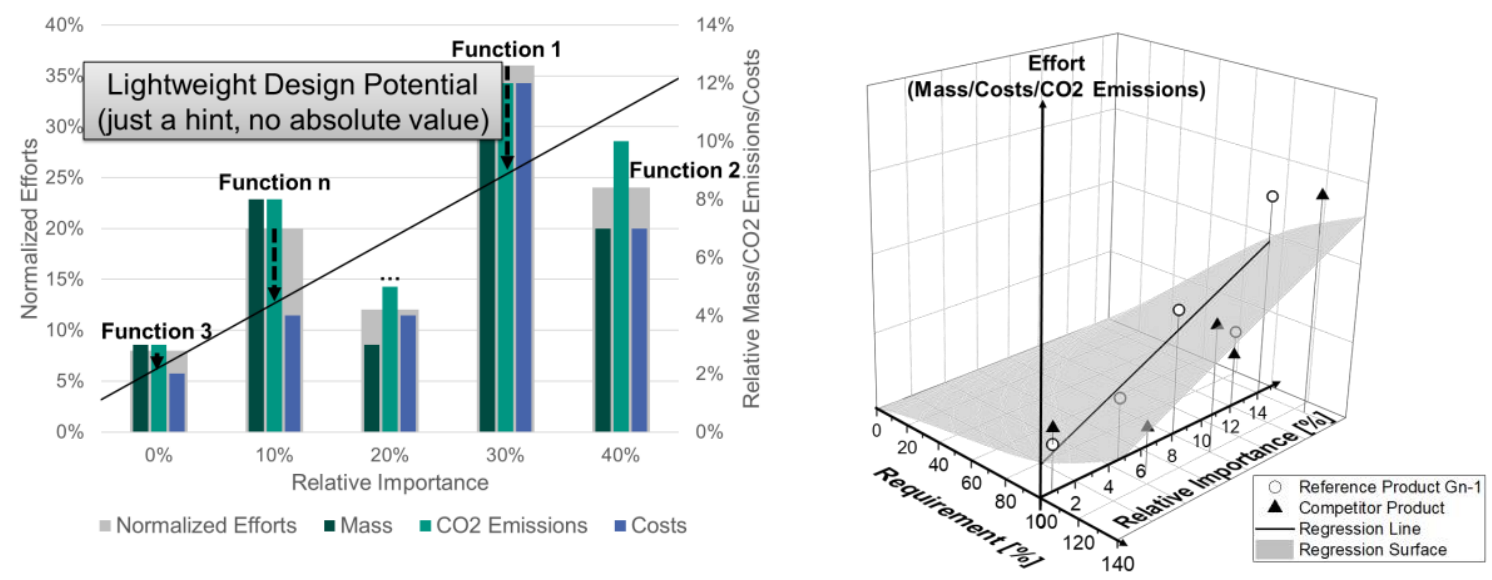

Figure 2. Function Portfolio (left) according to Albers et al. (2018) and Function Portfolio for Benchmarking (right) according to Albers et al. (2019) 


\subsection{Impact \& risk analysis}

When developing new design solutions in the product generation engineering process, an impact on other design embodiment elements, e.g. lightweight elements and the production system are very likely and lead to necessary changes. To evaluate the development risk, it is necessary to identify the change propagation of an occurring change (Eckert et al., 2004). For the visualization of interdependencies in products and to show the propagation of changes, matrices are established (Clarkson et al., 2001; Pimmler and Eppinger, 1994).

An interview study of Clarkson et al. (2001) states, that the interrelations between design elements are often unknown to the product development engineers and that there is often an unknown change propagation. They developed a method to rate the likelihood and impact of change propagation between product elements, and therewith the development risk (see Figure 3). This method allows an evaluation and rating of interdependencies between single product subsystems but does not include the production system.

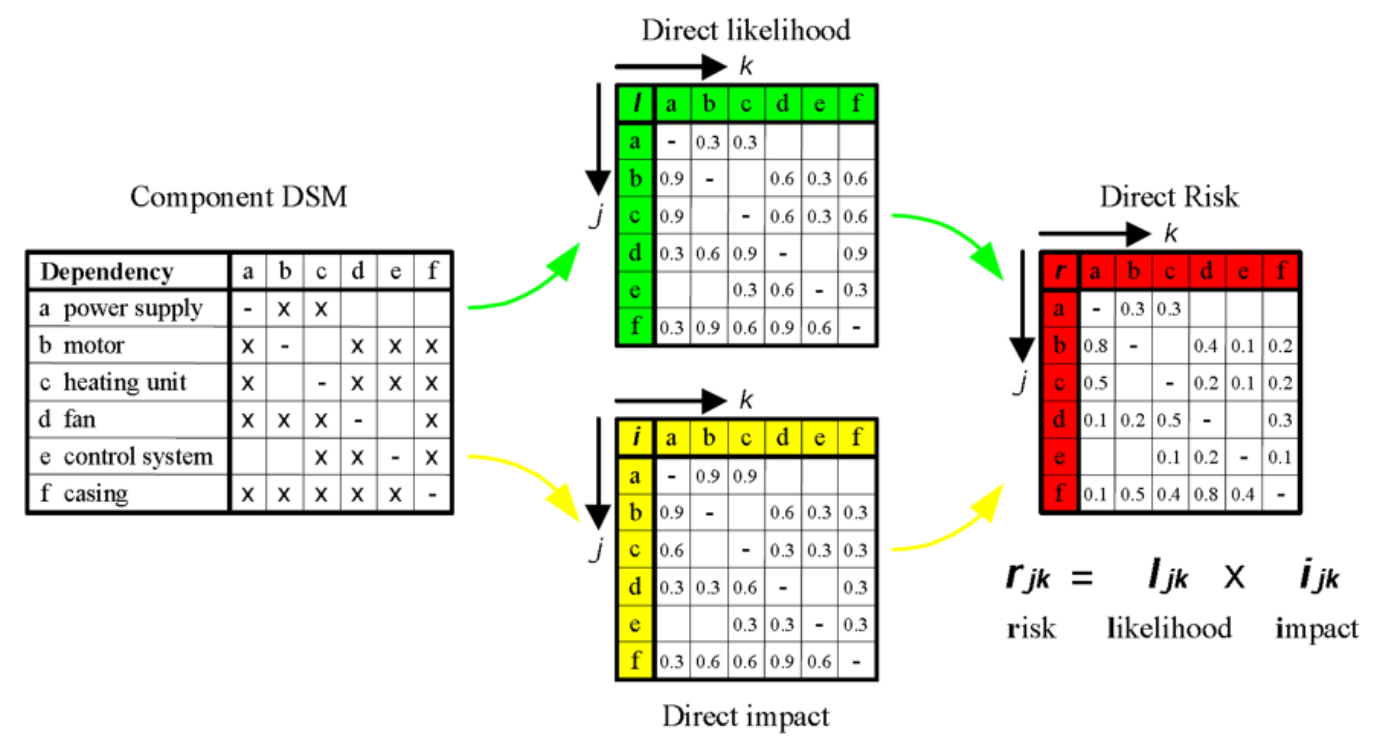

Figure 3. Direct likelihood, impact and risk matrices of product sub-systems (Clarkson et al., 2001).

On this basis, Gausemeier et al. (2012) model the interdependencies between product and production system in the aspects requirements, functions and components. This model is used for the evaluation of the robustness of a completely new developed product but does not include the use of information of a reference system. Stürmlinger et al. (2020) developed a method to display the change propagation of variations in the product and production system considering product functions, product embodiment, production processes, production machines and strategic factors. By including the production system, the method is complex in finding the interdependencies, however the likelihood and impact of changes are not calculated in detail to reduce the modelling effort. The matrix is displayed for a reference system in chapter 3.

For a holistic model in product development, the mentioned interdependencies can be modelled using Model Based Systems Engineering (MBSE), e.g. in SysML. This ensures the consistency and availability of information for the relevant stakeholders in the product engineering process. (Steimer $e t$ al., 2016; Mandel et al., 2020).

\section{APPROACH FOR PRODUCTION TECHNOLOGY TO FUNCTION}

Following the state of the art, this paper presents an approach that couples the lightweight design method ETWA with the impact and risk analysis for production systems. By doing so, a functionbased method is developed which allows the evaluation of lightweight design concepts with regard to the necessary production systems. The results indicate the underlying impact and risks which arise from the decision when heading for new lightweight design solutions. The impact and risk analysis is independent from lightweight design solutions in principle. However, the trend to MMD strengthens the demand for an impact and risk analysis due to the effects of different materials on the respective 
production processes and the strong interdependencies. This approach is a useful element for the product-production system co-design and can be transferred for different kind of design principles besides lightweight design.

The developed method is based on the ETWA and, essentially, on the Function-Effort-Matrix, which assigns the subsystems share of the function fulfilment. Through this matrix, the technical functions are directly linked to the product embodiment. By taking this as a basis, the impact matrix can be modelled as shown in Figure 4.

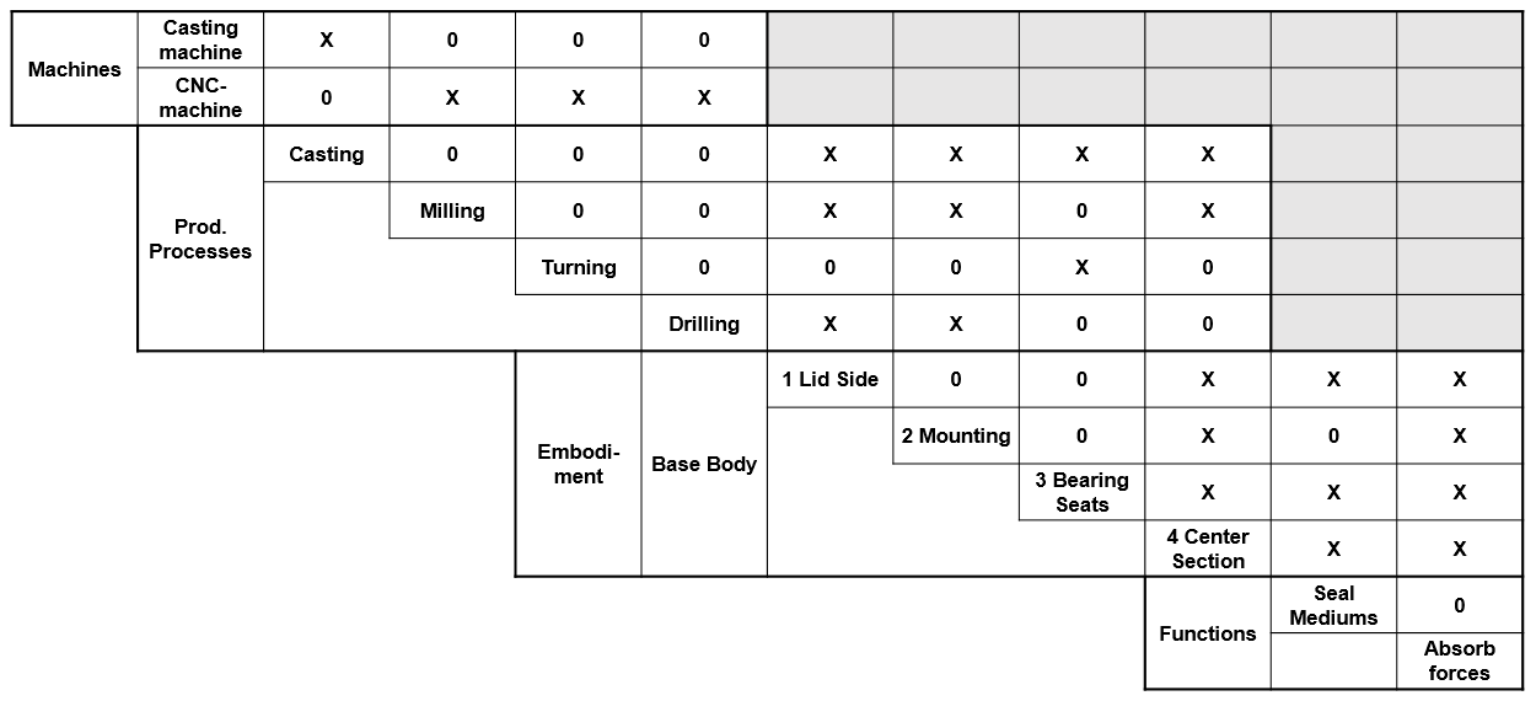

Figure 4. Impact matrix for the reference system including the gear box shown in chapter 4.1

The information is directly taken over from the ETWA analysis and complemented by the interdependencies between product embodiment and production processes, production machines and strategic factors like costs and throughput time. Figure 4 shows interdependencies between the single elements marked with "X", elements without interdependencies are marked with " 0 ". By enhancing ETWA with the impact matrix including the production system, the impacts of the production system to alternative lightweight design solutions can be investigated. When changing a product embodiment element in the product generation engineering process, the impacts to other product embodiment elements and to the production system get obvious. This supports the engineer in evaluating whether these impacts are relevant in the particular project and gives hints which system elements should be paid a larger attention to. For alternative solutions, the engineer can develop alternative impact matrices that are based on the reference matrix. Embodiment variations on the product side and attribute variations (see Albers et al. (2020a)) on the production system side are colored in the matrix, however principle variations mean that matrix elements have to be deleted or added. The matrix for an alternative solution of the reference system is shown in chapter 4.1.

The degree of change propagation $D_{C}$ indicates how strong other system elements are affected by a single change and is defined by the number of relevant change propagation $C_{r}$ divided by the sum of all total possible change propagation (the sum of all cells) $\sum C_{p}$. The cells for strategic influences are not considered in the calculation for alternative solutions (cf. application example in chapter 4.3).

$$
\mathrm{D}_{\mathrm{C}}=\frac{\mathrm{C}_{\mathrm{r}}}{\sum \mathrm{C}_{\mathrm{p}}}
$$

With the characteristic numbers $\partial_{\mathrm{N}}$ (see chapter 2.2) and $D_{C}$, the development risk $R_{D}$ of alternative solutions is displayed in Figure 5 and calculated in equation 2. 


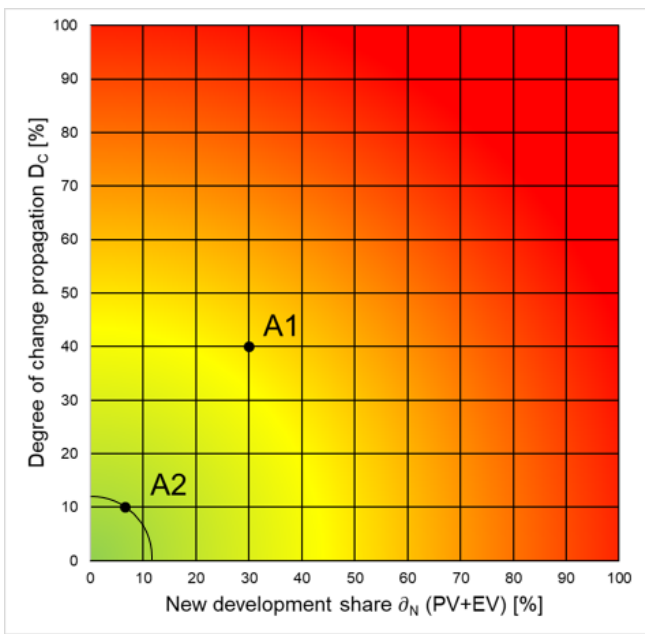

\begin{tabular}{|l|c|}
\hline \multicolumn{1}{|c|}{$\begin{array}{c}\text { Criticality of affected product } \\
\text { embodiment }\end{array}$} & $\begin{array}{c}\text { Factor } \mathrm{k}_{1} \text { for weighing } \\
\text { of } \partial_{\mathrm{N}}\end{array}$ \\
\hline High Criticality & $0,7-1,0$ \\
\hline Medium Criticality & $0,3-0,6$ \\
\hline Low Know-How & $0,0-0,3$ \\
\hline $\begin{array}{c}\text { Criticality of affected production } \\
\text { processes and machines }\end{array}$ & $\begin{array}{c}\text { Factor } \mathrm{k}_{2} \text { for weighing } \\
\text { of } \mathrm{D}_{\mathrm{C}}\end{array}$ \\
\hline High Criticality & $0,7-1,0$ \\
\hline Medium Criticality & $0,3-0,6$ \\
\hline Low Criticality & $0,0-0,3$ \\
\hline
\end{tabular}

Figure 5. Diagram for the visualization and comparison of development risks of alternative solutions (left), Indicators based on criticality for weighing the new development shares and degree of change propagation for each affected system element (right)

The factors $\mathrm{k}_{1}$ and $\mathrm{k}_{2}$ represent the weights of $\partial_{\mathrm{N}}$ and $\mathrm{D}_{\mathrm{C}}$ and are in the range between 0 and 1 . The factor $\mathrm{k}_{1}$ is introduced to weigh the new development share in the calculation of $\mathrm{R}_{\mathrm{D}}$. It has to be defined by the product developers, depending on the criticality of the variations. In general, PVs have a higher criticality and therewith risk than AVs. However, AVs can still be very critical, especially if it leads out of the boarders the company is familiar with or critical product functions are affected by it. In contrast, other AVs can have a very low risk, e.g. small variations that the company is familiar with.

$$
\mathrm{R}_{\mathrm{D}}=\sqrt{\left(\mathrm{k}_{1} \partial_{\mathrm{N}}\right)^{2}+\left(\mathrm{k}_{2} \mathrm{D}_{\mathrm{C}}\right)^{2}}
$$

Contrary to Clarkson et al. (2001), the criticality of the degree of change propagation - here expressed by the factor $\mathrm{k}_{2}$ - is not evaluated by conducting workshops for the likelihood and risk of these change propagations. In this contribution, the focus on the weight $k_{2}$ of $D_{C}$ is on the criticality of the production system variations. If there is a PV in the production processes, tools or machines, in general $\mathrm{k}_{2}$ is rated higher than for an $\mathrm{AV}$ which is often just a change of production process parameters or the change to a smaller or bigger tool. However also AVs of the production system can be very critical, e.g. if production processes come close to their process limits. Both factors $\mathrm{k}_{1}$ and $\mathrm{k}_{2}$ can be defined with little effort but are less precise then the mentioned approach by Clarkson et al. (2001). This is motivated by the aim of this research to model interdependencies and impacts in complex systems consisting of the product and production system with little effort to enable the application of the method for single development engineers or small teams.

To support the definition of the factors, Figure 5 (right) shows a classification depending on the criticality of product and production system variations:

For each affected system element, the weighing factor can be defined individually. For production processes or production machines and tools, the kind of variation and their criticality define how much the weight is. New principles in production often lead to a higher weight than well-known processes. The same counts for the embodiment variation of the product. The total factors of $k_{1}$ and $k_{2}$ are the sum of the single weights divided by the number of relevant elements.

\section{APPLICATION EXAMPLE}

The proposed approach for evaluating the production system impacts to lightweight design and functions is described in this chapter on a simplified use-case of a scooter gearbox housing.

\subsection{Modelling of the Reference System}

As a lightweight design development project, a fictitious company has received the task to reduce the mass of the scooter gearbox housing shown in Figure 6 (left). The reference product in the reference system consists of four components which are welded together. They are indicated with the numbers 1-4. The product developers decide to use the ETWA for lightweight optimization. In order to conduct the ETWA, they have analyzed the reference product with regard to its functions and their relative 
importance. Moreover, they assigned the components percentagewise to the functions in whose fulfilment they are involved. By doing so, they were able to set up the function portfolio shown in Figure 6 (right). Based on this, the functions indicating lightweight design potential have been derived: (a) Dissipate heat, (b) Seal against medium intrusion, (c) Absorb axial forces and (d) Absorb bending moments. The subsystem, which contributes to all four functions and also has a high mass, is the center section (4). For a better overview and to enable a better comprehensibility of the method for this simplified example, the paper from here on focusses on just two functions namely "Seal against medium intrusion" (short: "seal mediums") and "Absorb axial forces" (short: "absorb forces").

The company developing and producing the gearbox is a medium-sized company. The simplified reference production system consists of a CNC-machine for milling, turning and drilling and a casting machine.
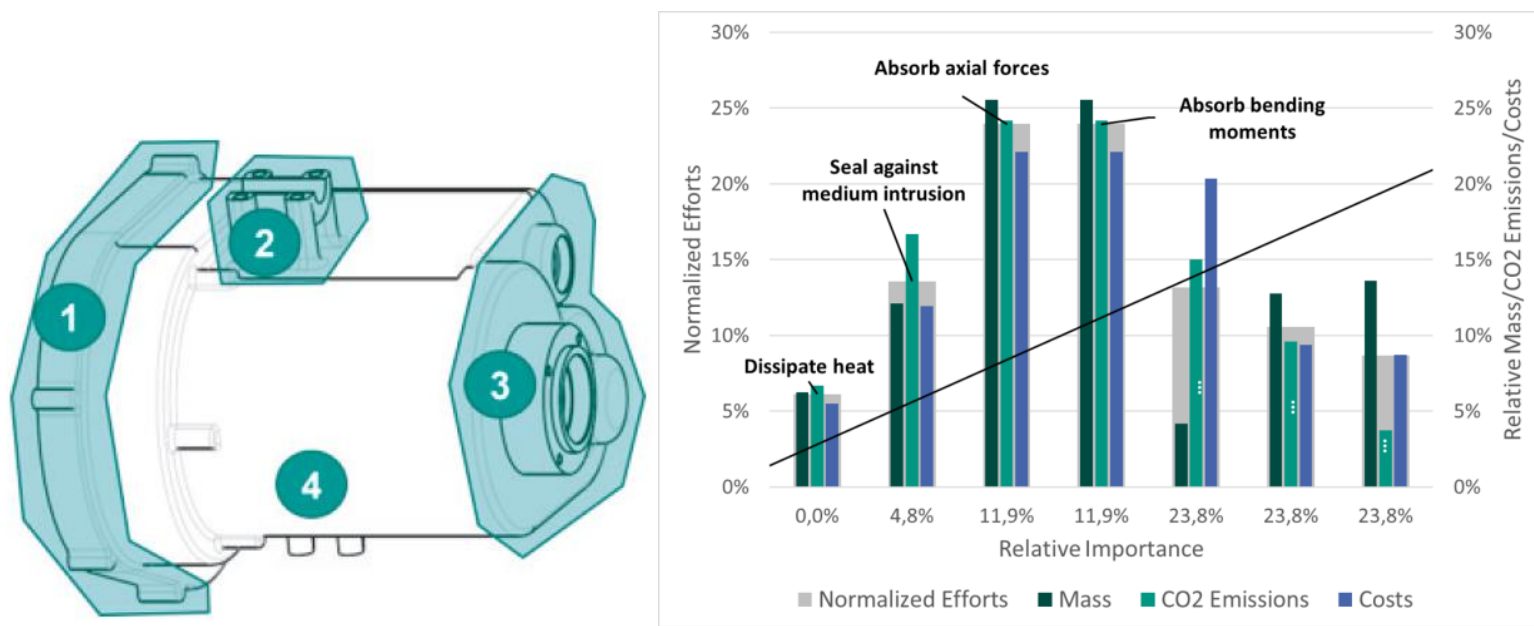

Figure 6. (left) Reference product (Albers et al., 2017), (right) Function portfolio according to Albers et al. (2020b)

In Figure 4, the reference system with its interdependencies is modelled. The four product embodiment elements belong to the housing and are all casted before they get milled, drilled or turned. It can be seen that there are 24 out of 45 possible interdependencies in the reference system. Strategic factors are not modelled in the reference system, because they are just modelled for alternative solutions relatively to the reference system.

\subsection{Concept Evaluation}

Based on the four identified functions which indicate lightweight design potential (see Figure 6 (right)), the product developers decided to generate new designs for the center section with the use of creativity methods. As a result, they developed a multi-material concept by adding a polymer insert. Thus, a separation of the function "seal mediums" has been realized. The MMD concept is shown in Figure 7.

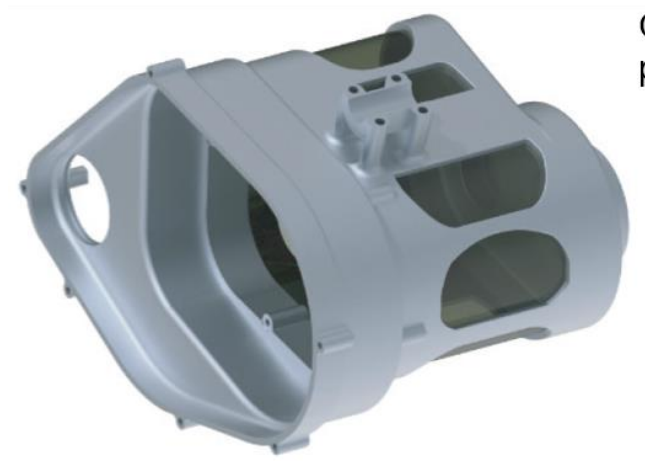

Contact surface between Cap with bearing seats and polymer insert

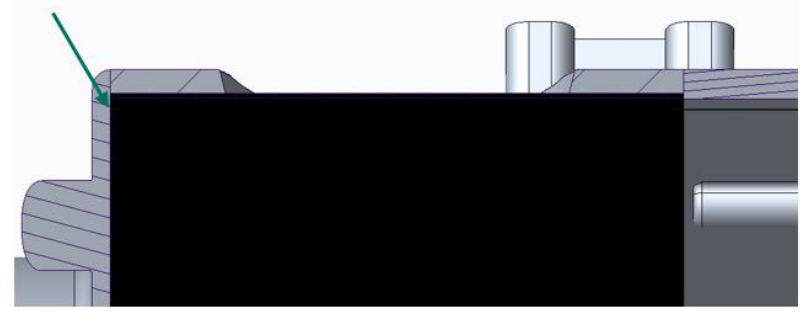

Figure 7. Concept for an alternative lightweight solution (left), detailed section view of the polymer insert (right) 


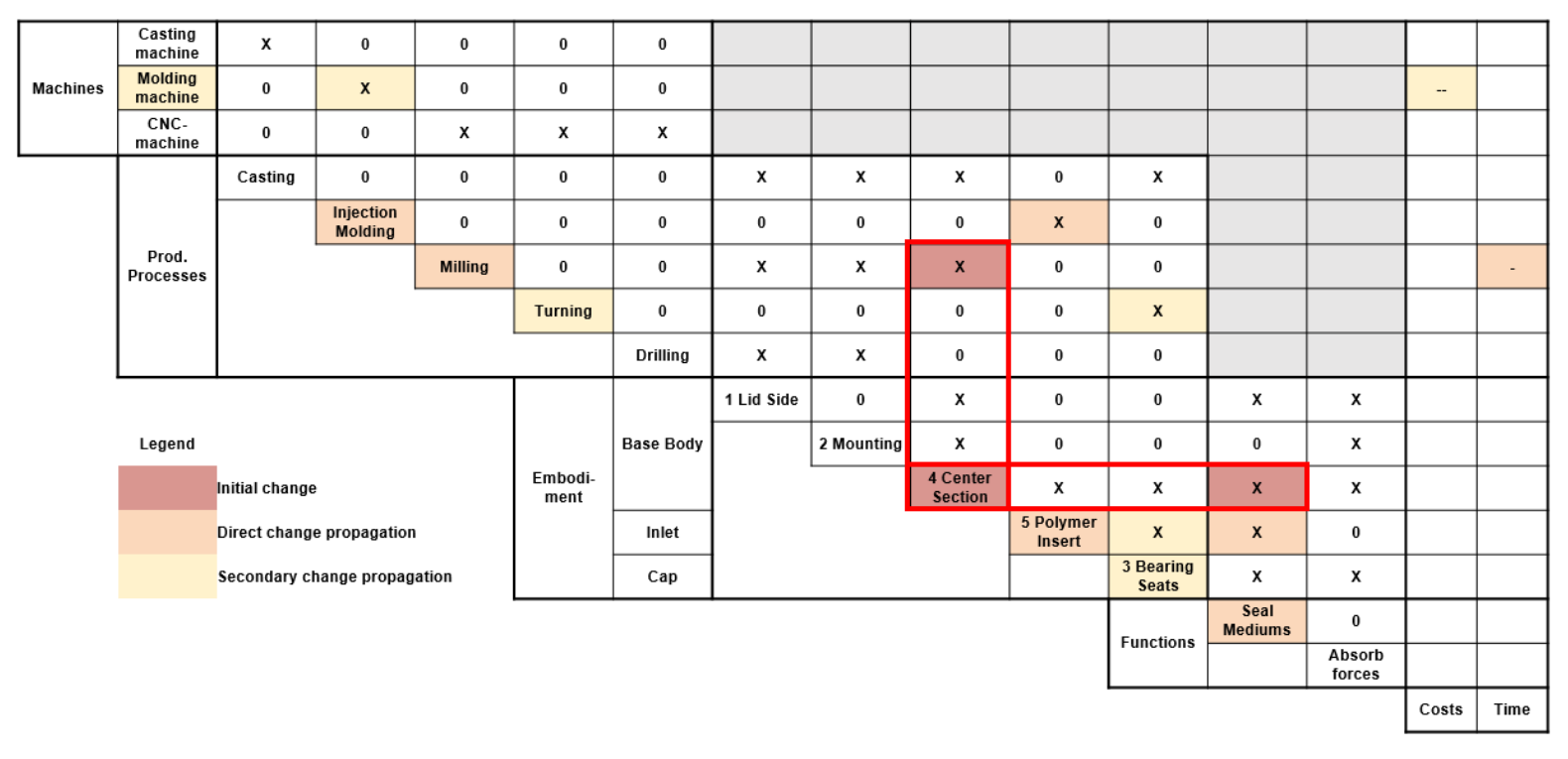

Figure 8. Impact matrix of the new gear box design

Following the impact matrix in Figure 8, the initially changed design of the "center section" has possible impacts on all other product embodiment elements as they are directly attached to it, as well as on both functions and on the production processes "milling" and "casting". By evaluating the kind of design change, the product developers realize that the integrated gaps just affect the milling process and not the upstream casting process. Same counts for the other possible impacts: In this case, the impacts are not relevant, except the affected function "seal mediums". The changed design of the "center section" leads to an initial change of the belonging "milling process" due to more production time needed compared to the reference design and has the effect, that the function "seal mediums" can't be fulfilled anymore due to the holes. In a first change propagation, this means that the function has to be fulfilled by another element, the newly integrated "polymer insert", which is manufactured by "injection molding" in a "molding machine". This machine is not part of the previous production system generation, which means it leads to high investment costs. Due to the polymer insert design, the assembly has to be done from the backside, and the contact surface of the "bearing seats" has to be produced with higher requirements to the surface quality (see Figure 7 (right)), which means a secondary change propagation from the design change of the "center section". By the change of the "bearing seats", its "turning" process is changed. In this example, the product and production engineers can conclude, that the change of the "center section" design has an impact on the "turning" process of another embodiment element. This interdependency is no obvious correlation, so the engineers are supported by evaluating impacts of changes by a multi-step analysis of the change propagation. This gives a clear hint, which product and production system elements have to be considered in the product generation engineering process and can help to estimate the development risk.

\subsection{Risk analysis}

To evaluate the development risk of the described example, according to chapter 2 the new development shares are calculated and combined with the degree of change propagation (see chapter 3 ).

In the example, the number of relevant change propagation $C_{r}$ is 7 , the number of possible change propagation $\sum C_{p}$ is 71 . According to equation 1, the degree of change propagation $D_{C}$ is 0.0985 $(9.85 \%)$. The production processes "Milling" and "Turning" are affected little because it is just an AV with a change of the process parameters. Therefore, considering Figure 5 (right) their individual weight is estimated to 0.1 . In contrast, the newly required production process "Injection Molding" with the new "Molding Machine" shows a high weight of 1.0 because the company has no know-how in this process which leads to a high criticality. All in all, the factor $\mathrm{k}_{2}$ is $(0.1+0.1+1.0+1.0) / 4=0,55$.

Out of the five embodiment elements, the "lid side (1)" and the "mounting (2)" are carried over in the new product generation. The "center section" is a principle variation because material is removed and gaps are created. The new "polymer insert" is another PV, while the variation of the "Bearing Seat" is 
an embodiment variation. The new development share is therewith calculated to $60 \%$. The weight of the two carried over embodiment elements is determined to 0.0. Due to the "polymer insert" is a new part, its weight is determined to 1.0 and the "center section" with a non-critical PV to 0.5 . In total, $\mathrm{k}_{1}$ is $(0.0+0.0+1.0+0.5) / 4=0.375$.

The total development risk $R_{D}$ for this integrated development task is 0.23 according to equation 2 . The risk value supports the product and production system developers in decision making between different alternative solutions. The risk value gives orientation and decision support if two or more alternative solutions are compared and thus evaluated for the lowest risk.

\section{CONCLUSION \& OUTLOOK}

By applying the ETWA, product subsystems are assigned to product functions to identify lightweight design potentials. On this basis, alternative solutions to optimize the product mass can be designed. The interrelations between product functions and product embodiment are complemented by the respective production processes and machines in an impact matrix that can be set up for the reference system and the alternative solutions. Using the impact matrix, the product and production system developers can analyze the impact of changes and calculate the change propagation. By combining the change propagation with the new development share of an alternative solution, the development risk can be calculated considering the weights of single impacts and product embodiment variations.

It can be concluded that this approach supports product developers, production system developers and development teams in evaluating the impact of changes within and between the different domains and to estimate development risks. Depending on the level of maturity of alternative solutions and the knowledge of interrelations between production system and product development, the level of detail in the modelling can be varied. The method gives a good overview and support in decision making with little modelling effort, however can lack in accuracy due to the easy approach of weighing the single impacts and product embodiment variations. Furthermore, the evaluation of the criticality of impacts is dependent on subjective estimations. The proposed approach is applicable to different kinds of development tasks and application cases due to its generic character.

In a next step, the coherent ETWA and impact analysis can be implemented in a software tool, e.g. under application of Model Based System Engineering (MBSE) to ensure consistency and to simplify the evaluation of development risks by automating the analysis of the model. To this end, the authors will build on previous research where the ETWA has already been linked to MBSE (Albers et al., 2018).

\section{ACKNOWLEDGMENTS}

The research documented in this manuscript has been partly funded by the German Research Foundation (DFG) within the International Research Training Group "Integrated engineering of continuous-discontinuous long fiber reinforced polymer structures" (GRK 2078). The support by the German Research Foundation (DFG) is gratefully acknowledged.

\section{REFERENCES}

Albers, A., Bursac, N. and Wintergerst, E. (2015), "Produktgenerationsentwicklung-Bedeutung und Herausforderungen aus einer entwicklungsmethodischen Perspektive", Stuttgarter Symposium für Produktentwicklung.

Albers, A., Moeser, G. and Revfi, S. (2018), "Synergy Effects by using SysML Models for the Lightweight Design Method "Extended Target Weighing Approach"', in 28th CIRP Design Conference, Nantes, May 23-25, 2018, Vol. 70, Elsevier, Amsterdam, pp. 434-439.

Albers, A., Rapp, S., Fahl, J., Hirschter, T., Revfi, S., Schulz, M., Stürmlinger, T. and Spadinger, M. (2020a), "Proposing a generalized description of variations in different types of systems by the model of PGE Product Generation Engineering”, Proceedings of the Design Society: DESIGN Conference, Vol. 1, pp. 2235-2244.

Albers, A., Revfi, S., Kraus, F. and Spadinger, M. (2019), "Function-based benchmarking to identify competitorbased lightweight design potentials", Procedia CIRP, Vol. 84, pp. 526-531.

Albers, A., Revfi, S. and Spadinger, M. (2017), "Extended Target Weighing Approach - Identification of Lightweight Design Potential for New Product Generations", in Proceedings of the 21st International Conference on Engineering Design (ICED 17), Vancouver, August 21-25, 2017, Vol. 4: Design Methods and Tools, The Design Society, Glasgow, pp. 367-376. 
Albers, A., Revfi, S. and Spadinger, M. (2020b), "Funktionsbasierte Entwicklung leichter Produkte", in Henning, F. and Moeller, E. (Eds.), Handbuch Leichtbau: Methoden, Werkstoffe, Fertigung, 2., überarbeitete und erweiterte Auflage, Hanser, München, pp. 133-152.

Albers, A., Wagner, D., Ruckpaul, A., Hessenauer, B., Burkardt, N. and Matthiesen, S. (2013), “Target Weighing - A New Approach for Conceptual Lightweight Design in Early Phases of Complex Systems Development", in Proceedings of the 19th International Conference on Engineering Design (ICED 13), Seoul, August 19-22, 2013, The Design Society, Glasgow, pp. 301-310.

Clarkson, P.J., Simons, C. and Eckert, C. (2001), "Predicting Change Propagation in Complex Design", Proceedings ASME Design Engineering Technical Conferences and Computers and Information in Engineering Conference.

Eckert, C.M., Clarkson, P.J. and Zanker, W. (2004), "Change and customisation in complex engineering domains", Research in Engineering Design, Vol. 15 No. 1, pp. 1-21.

Feyerabend, F. (1991), Wertanalyse Gewicht: Methodische Gewichtsreduzierung - am Beispiel von Industrierobotern, VDI-Verlag.

Frankenberger, E., Badke-Schaub, P. and Birkhofer, H. (1998), Designers: The Key to Successful Product Development, Springer London, London.

Gausemeier, J., Lanza, G. and Lindemann, U. (2012), Produkte und Produktionssysteme integrativ konzipieren: Modellbildung und Analyse in der frühen Phase der Produktentstehung, 1. Aufl., Carl Hanser Verlag $\mathrm{GmbH} \& \mathrm{Co} . \mathrm{KG}$.

Kopp, G., Burkardt, N. and Majic, N. (2011), "Leichtbaustrategien und Bauweisen”, in Henning, F. and Moeller, E. (Eds.), Handbuch Leichtbau, Carl Hanser Verlag.

Laufer, F., Roth, D. and Binz, H. (2019), "Derivation of Criteria for Identifying Lightweight Potential - A Literature Review", Proceedings of the Design Society: International Conference on Engineering Design, Vol. 1 No. 1, pp. 2677-2686.

Lindemann, U. and Reichwald, R. (Eds.) (1998), Integriertes Änderungsmanagement, Springer-Verlag, Berlin, Heidelberg.

Mandel, C., Stürmlinger, T., Yue, C., Behrendt, M. and Albers, A. (2020), "Model-Based Systems Engineering Approaches for the integrated development of product and production systems in the context of Industry 4.0”, in IEEE (Ed.), SysCon 2020: 14th Annual IEEE International Systems Conference.

Pimmler, T.U. and Eppinger, S.D. (1994), "Integration Analysis of Product decompositions", Proceedings ASME International Design Engineering Technical Conferences.

Ponn, J. and Lindemann, U. (2011), Konzeptentwicklung und Gestaltung technischer Produkte: Systematisch von Anforderungen zu Konzepten und Gestaltlösungen, VDI-Buch, 2. Aufl., Springer-Verlag Berlin Heidelberg, Berlin, Heidelberg.

Posner, B., Binz, H. and Roth, D. (2013), "Operationalisation of the Value Analysis for Design for Lightweight. The Function Mass Analysis”, in Proceedings of the 19th International Conference on Engineering Design (ICED 13), Seoul, August 19-22, 2013, The Design Society, Glasgow, pp. 271-280.

Reinhart, G., Lindemann, U. and Heinzl, J. (1996), Qualitätsmanagement: Ein Kurs für Studium und Praxis, Springer-Verlag, Berlin.

Steimer, C., Fischer, J., Cadet, M., Meissner, H., Aurich, J.C. and Stephan, N. (2016), "SysML-basierte Planung cybertronischer Produktionssysteme in frühen Entwicklungsphasen”, in Schulze, S.-O., Tschirner, C., Kaffenberger, R., Ackva, S., GfSE Gesellschaft für Systems Engineering e.V. and TdSE 25.-27.10.2016 (Eds.), Tag des Systems Engineering, München, Carl Hanser, pp. 365-374.

Stürmlinger, T., Jost, D., Mandel, C., Behrendt, M. and Albers, A. (2020), "Impact and risk analysis in the integrated development of product and production system”, Procedia CIRP, Vol. 91, pp. 627-633. 